\title{
Towards sustainable development and self-sufficient communities in the rural areas of Egypt
}

\author{
M. Z. Ayman \\ Department of Architecture, Faculty of Engineering, \\ Alexandria University, Egypt
}

\begin{abstract}
Egypt is a unique country, thanks to its special geographical location in the world. From that leading role certain actions ought to be taken to put Egypt on the right track of development and to achieve benefits through sustainable development.

Sustainable development in Zamarna Village was achieved and the volume of achieved development was ensured using its ecological footprint as an indicator of sustainability, which the village had in 2016. It had an ecological footprint far more than its carrying capacity and after applying the experiment the current footprint has been less than its carrying capacity. Through applying principles of sustainable development along with the useful theoretical framework from the Zamarna Village experiment and considering the nature of urban composition in Egypt, we can put the general framework of sustainable development and selfsufficient communities in the rural areas of Egypt.

This research considers how to achieve sustainable development in the rural communities where work is done in three integrated main categories, namely, the socially restorative community, economical self-sufficiency and regenerative ecological capital. The objectives of this research can be summarized as follows.

To understand what the environment of rural areas is and what it is composed of, as well as to define the mutual impact of each component on the other, studying and analyzing "Zamarna Village" as an experiment to use the useful theoretical framework, putting a model to achieve sustainable development and self-sufficient communities in the rural areas of Egypt.

Keywords: sustainable development, self-sufficient communities, rural area, ecological footprint, socially restorative community, economical self-sufficiency, regenerative ecological capital.
\end{abstract}




\section{Introduction}

Egypt is challenged to achieve sustainable development as the populated area in Egypt (40,510 square kilometers) does not exceed $4.1 \%$ of the total area $(1,000,000$ square kilometers). The estimated rural area in Egypt is (36,330 square kilometers), which represents $(89.7 \%)$ of the total populated area, and the inhabited (50.4 million people), representing $57.3 \%$ of Egypt's population (88 million people) (CAPMAS [1]).

These illustrate the great importance for achieving sustainable development in rural areas in Egypt and for that the assumptions of this research can be summarized by posing these questions:

- Can we achieve sustainable development in the rural areas of Egypt?

- Can we measure how far the rural areas of Egypt are sustained?

- What is the mechanism to achieve sustainable development in the rural areas of Egypt?

\section{Sustainable development}

Sustainable development is a program of action for local and global economic reform and it is a program that has yet to be fully defined. The challenge of this new program is to develop, test, and disseminate ways to change the process of economic development so that it does not destroy the ecosystems and the community systems; at the local level, sustainable development requires that the local economic development supports community life, using the talents and resources of the local residents. It further challenges us to distribute the benefits of development equitably, and to sustain these benefits for all social groups over the long term. This can only be achieved by preventing the waste of ecological wealth and the degradation of ecosystems by economic activities (Wackernagel and Rees [2]).

There are always three distinct development processes at the local level which are economic, community, and ecological development. Each of these processes has its own distinct imperatives. The development imperatives of the current economic system favor market expansion, externalization of costs and sustained private profit. The current imperatives of community development should meet basic human needs, increase economic and social equity, and create community self-reliance.

Humans can support ecological development by limiting the consumption of natural resources to a rate that allows nature to regenerate resources and by reducing the production of waste to levels that can be absorbed by natural processes. The imperatives of these development processes often contradict one another (IDRC [3]).

\subsection{Ecological footprints as indicators of sustainability}

The ecological footprint concept is simple, it accounts for the flows of energy and the matters to and from any defined economy and converts these into the 
corresponding (land/water) area required from nature to support these flows. The ecological footprint is about humanity's continuing dependence on nature and what we can do to secure the Earth's capacity to support a humane existence for all in the future. Understanding our ecological constraints will make our sustainability strategies more effective and reliable. Ecological footprint analysis should help us to choose wisely to achieve the main goal (Chambers et al. [4]).

\section{Case study of Zamarna Village's experiment}

Zamarna Village is one of the villages of Central Damanhur, Beheira Governorate. It is famous for setting up public projects with individual efforts: full-services village (sanitation - paved roads - portable water - telephones - electricity). One of the most important things is the absence of slums with the prescience of a population of 2375 citizens living in an area of $1.1 \mathrm{~km}^{2}$ in the year 2016 (Elboheira Governorate [5]).

Zamarna Charity: most of Zamarna's citizens are members of charity and it consists of a board of directors that consists of 9 members. They expend their maximum efforts in a constant search for what's new and advanced, as well as pushing the wheel of construction and development. Facing many public problems which preoccupy the whole of Egyptian society, such as public health problems, unemployment which affect every household, the problem of improving incomes to face high prices and cost of living.

After determining the real needs of the village and its capabilities, many meetings and cultural forums were held for villagers since the declaration of the association in 1989 to achieve the following goals: raising the ecological awareness of citizens to the ecological problems, as well, studying the causes, effects, and ways of confronting it.

By formulating the concept of societal sharing, the importance of team work, encouraging citizens to practice this concept and multi-frequent visits to the village by many of the officials, the public, executive leaderships, political experts and civil associations and clubs.

This effort has been implemented through concerned sides of culture -making like general administration of village - the cultural directorship of Beheira - the rural development project in Beheira - the Rotary club in Dammanhour businessmen association in Beheira governorate - environment affairs system.

After reviewing the general problems and determining each problem separately all people were engaged through forums and group meetings where creative youthful thought started to reach some solutions regarding problems as follows:

\subsection{Effects of the practice on public health}

Concerning public health in a village means facing many challenges such as, streams, flies, spread of infections, incorrect habits and traditions. All that effect in surrounding ecological elements and public health. 


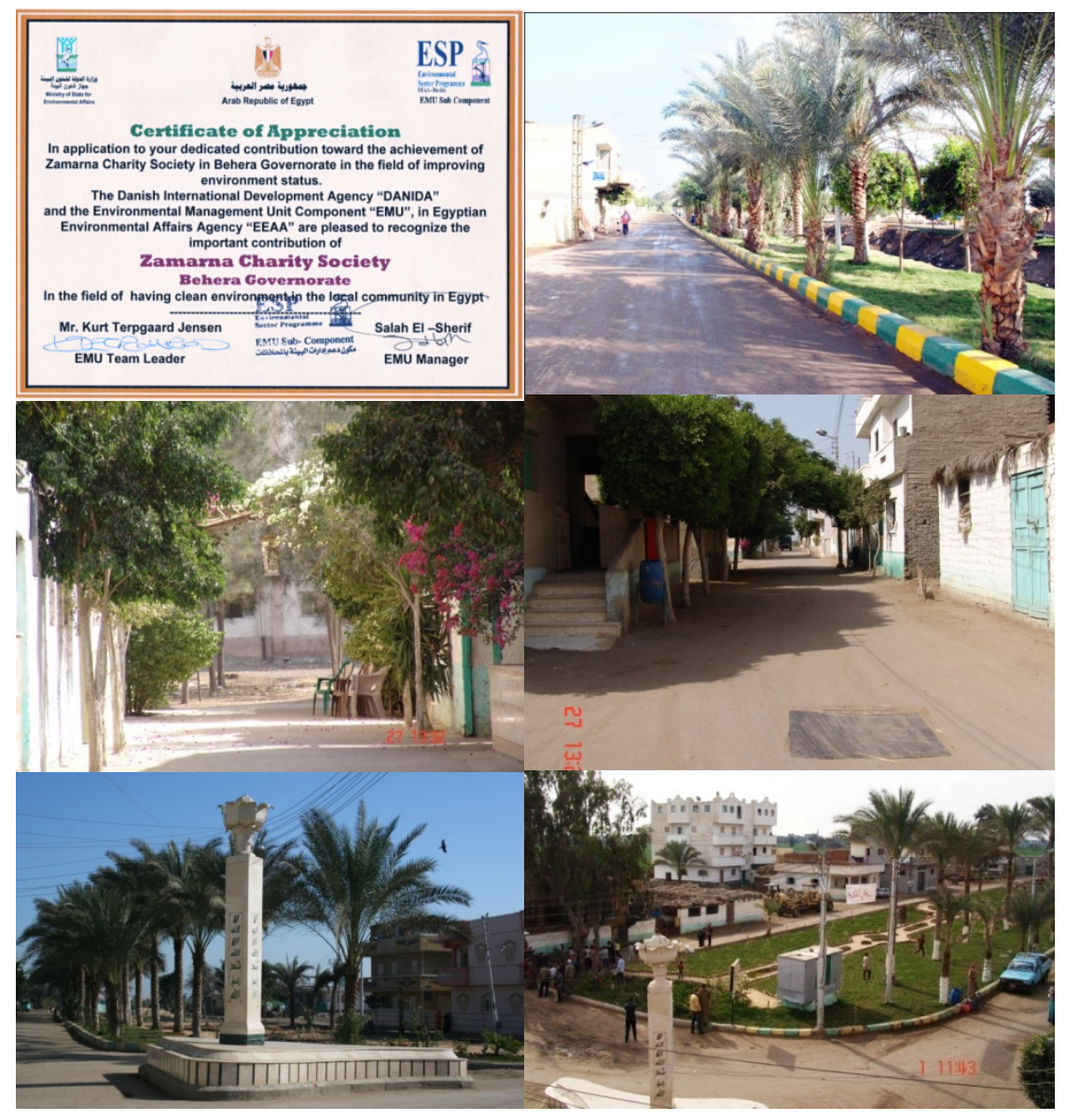

Figure 1: Zamarna Village in images.

\subsubsection{Problem elements}

The surrounding environment and how to deal with it (village elements: people; plants; animals; birds) and each has residual products, which affects the environment positively and negatively.

Effects of the environment elements appear in the houses, streets, and in the farms.

The presence of channels and streams in the village made them misused by the villagers, which definitely affects the public health.

Individuals in the rural communities do not receive enough health awareness and they have many bad health habits. 


\subsubsection{Suggestion of suitable solutions}

The starting point here is to confirm the idea of cleanliness and dealing with garbage and waste through proper ecological ways and changing behavior in order to achieve that goal, which is managed by holding many scientific and cultural meetings for all the inhabitants, by providing the village streets with garbage bins and plastic waste baskets, encouraging citizens to collect and sort garbage in the house continuously and dividing into organic garbage, non-organic garbage and hazardous garbage, making people aware of the danger of using waste water in the channels and streams and the danger of throwing dead birds into the water.

\subsubsection{Results of suggested solutions}

In transferring the level of cleanliness in the village into a more urban and remarkable level than before. The most influential thing on people's minds and exciting competition among them is to maintain cleanliness and to beautify streets.

Piling up rice husks and converting them into animal feed rather than getting rid of them through burning and polluting the environment with black smoke.

All that led to the change of the eco-manners of people of all ages and of both genders. Thus, the generation of natural energy will create positive behavior in the houses, streets and farms and even in dealing with cattle and birds, making the ecological style the norm in all aspects of village life and thus the positive behavior will serve the public health.

\subsection{Effects of the practice on making a living}

In dealing with unemployment and in an attempt to improve the incomes to face the rising prices and the living conditions, many meetings were held by the natural leaders at Village Zamarna through Zamarna Charity in a wave of constructively handling the problem as follows:

\subsubsection{Problem factors}

With unemployed youths, defining the different factors and finding the link between them to determine the way of confrontation, suggesting projects by linking the different eco factors. Projects, actions and creating job opportunities need financial capital.

\subsubsection{Suggesting suitable solutions}

The most important goals of Zamarna Charity are to provide social services and contributions for the poor, in which field the association has an eminent role.

The association built a school complex comprising of five schools: KG, primary school, preparatory male and female schools as well as a secondary school and a single-class school, in addition to an Islamic school complex.

Those things helped a lot in finding work opportunities for youth and amounted to 152 chances for the villagers. In facing the problem, a few projects were set up to serve the environment and keep up with the inter-related factors, so the rural development project in Beheira Governorate played a big role in providing the necessary fodder for veal projects at low prices to encourage the process. 


\subsubsection{The results}

Establishing a rabbit battery project for the limited-income people in cooperation with the Rural Development Project in Beheira Governorate and in one year 5 projects were established for 10 youths.

Establishing a nursery project for ornamental plants in which 3 youths are cooperating.

A cleanliness project previously mentioned in which 2 youths are mandated with transferring and collecting garbage in their local areas.

Setting up 2 welding workshops for 10 young workers.

Establishing 1 apiary for honey bees with 3 youths and 18 cattle feeding projects for producing meat with 40 young workers.

Establishing a factory for recycling plastic and the production of plastic bags with 15 young workers.

Setting up six greenhouses with 30 young workers and setting up 19 dairy products projects, 51 micro projects, poultry-feed factory, rice-sorting and packing factory, wheat-grinding and flour preparing factory with over 100 young workers (Ismaiel [6]).

The results of applying the suggested solutions are solving unemployment for the majority of the villagers through providing honorable work opportunities, finding chances to improve income by developing and improving micro-projects to become small projects, finding the link between projects integrally which may achieve harmony, solidarity and success, acquiring experience in different fields of work with the young, so they can improve, develop and achieve better results, limiting the illegal immigration outside the village to provide opportunities for the village's youth and to reduce the immigration gradually, as illegal immigration is banned nowadays. All these solutions could lead to positive changes in the ecological conduct, helping a lot in solving the citizen's problems and creating job opportunities for the youth.

\subsection{Role of the local citizens in the practice}

One of reasons for achieving success is the interaction of the local leaders in the village and the serious trials to find real solutions through field experience and community sharing on the one hand; and on the other hand, the local citizens are seriously desirous to find solutions for the general problems. This encouraged the citizens to find positive results that should be achieved and reflected upon them with benefits. By creating the spirit of positive sharing that manifested itself in many scenes proved the power of sharing, size of sacrifice and the speed of response. All the inhabitants participated in providing the necessary finance and in setting up public projects, services and all the elements of practice locally and individually within the village. Effective participation of all the inhabitants in all the forums and meetings held in the village which all served the suggestions for solutions to the public problems and the participation of all children in picking up trash and garbage for proper disposal.

The results were the positive change of conduct towards the environment elements in the rural community. 


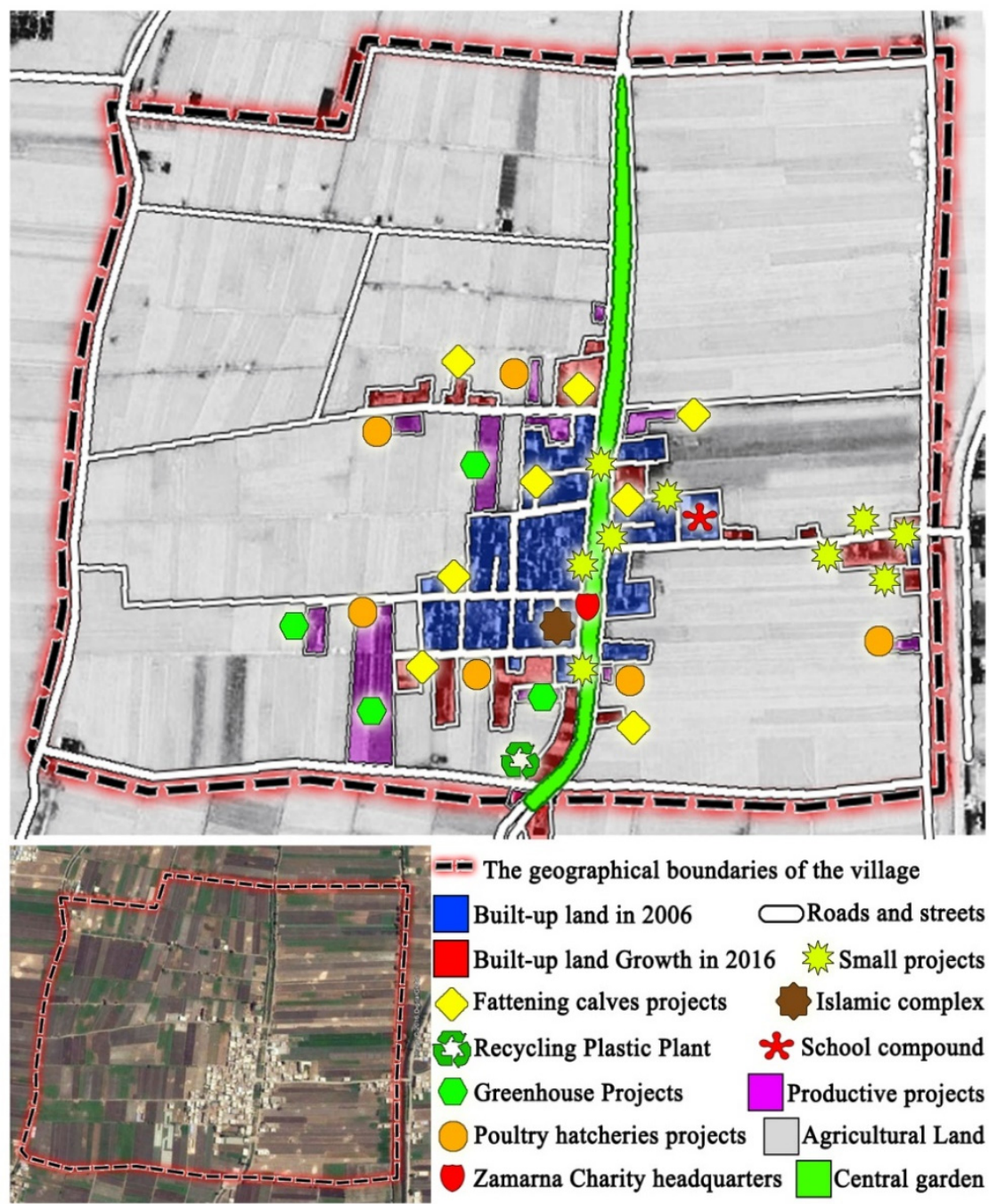

Figure 2: Sustainable development and self-sufficient communities in the rural areas of Egypt.

\section{The ecological footprint of Zamarna Village}

To calculate the ecological footprint, we should know that the ecological load of an individual in Zamarna is the land area over population, that is 1.1 square $\mathrm{km}$ over 2375 people on 463 square meters in the year 2016. The ecological footprint which is the area of land necessary for producing what village use in a year and is calculated by 6 main elements covering all aspects of life, such as production and consumption. 
The ecological footprint in 2006 was 580 square meter per person, in 2010 was 63 square meters per person, and in 2016 is 1 square meter per person.

All these calculations were based on equations from the book "Sharing Nature's Interest" (Chambers [4]), and depending on field data (Ismaiel [6]), Elboheira Governorate information center (Elboheira Governote [5]) and the Censuses of Egypt (CAPMAS [7-9]).

Table 1: The ecological footprint of Zamarana Village.

\begin{tabular}{|l|l|l|l|}
\cline { 2 - 4 } \multicolumn{1}{c|}{} & \multicolumn{1}{c|}{2006} & \multicolumn{1}{c|}{2010} & \multicolumn{1}{c|}{2016} \\
\hline Ecological foot print of energy & $600000 \mathrm{~m}^{2}$ & $650000 \mathrm{~m}^{2}$ & $670000 \mathrm{~m}^{2}$ \\
\hline Ecological foot print of transport & $35000 \mathrm{~m}^{2}$ & $38000 \mathrm{~m}^{2}$ & $40000 \mathrm{~m}^{2}$ \\
\hline Ecological foot print of material and waste & $356000 \mathrm{~m}^{2}$ & $54000 \mathrm{~m}^{2}$ & $90000 \mathrm{~m}^{2}$ \\
\hline Ecological foot print of food & $2000 \mathrm{~m}^{2}$ & -810000 & -1170000 \\
\hline Ecological foot print of water & $1000 \mathrm{~m}^{2}$ & $1080 \mathrm{~m}^{2}$ & $1200 \mathrm{~m}^{2}$ \\
\hline Ecological foot print of built-up land & $196000 \mathrm{~m}^{2}$ & $208000 \mathrm{~m}^{2}$ & $370000 \mathrm{~m}^{2}$ \\
\hline Total ecological foot print & $1196000 \mathrm{~m}^{2}$ & $141080 \mathrm{~m}^{2}$ & $1200 \mathrm{~m}^{2}$ \\
\hline Population & $2050 \mathrm{p}$. & $2235 \mathrm{p}$. & $2375 \mathrm{p}$. \\
\hline Ecological foot print per person & $580 \mathrm{~m}^{2}$ & $63 \mathrm{~m}^{2}$ & $1 \mathrm{~m}^{2}$ \\
\hline The ecological load per person & $537 \mathrm{~m}^{2}$ & $492 \mathrm{~m}^{2}$ & $463 \mathrm{~m}^{2}$ \\
\hline
\end{tabular}

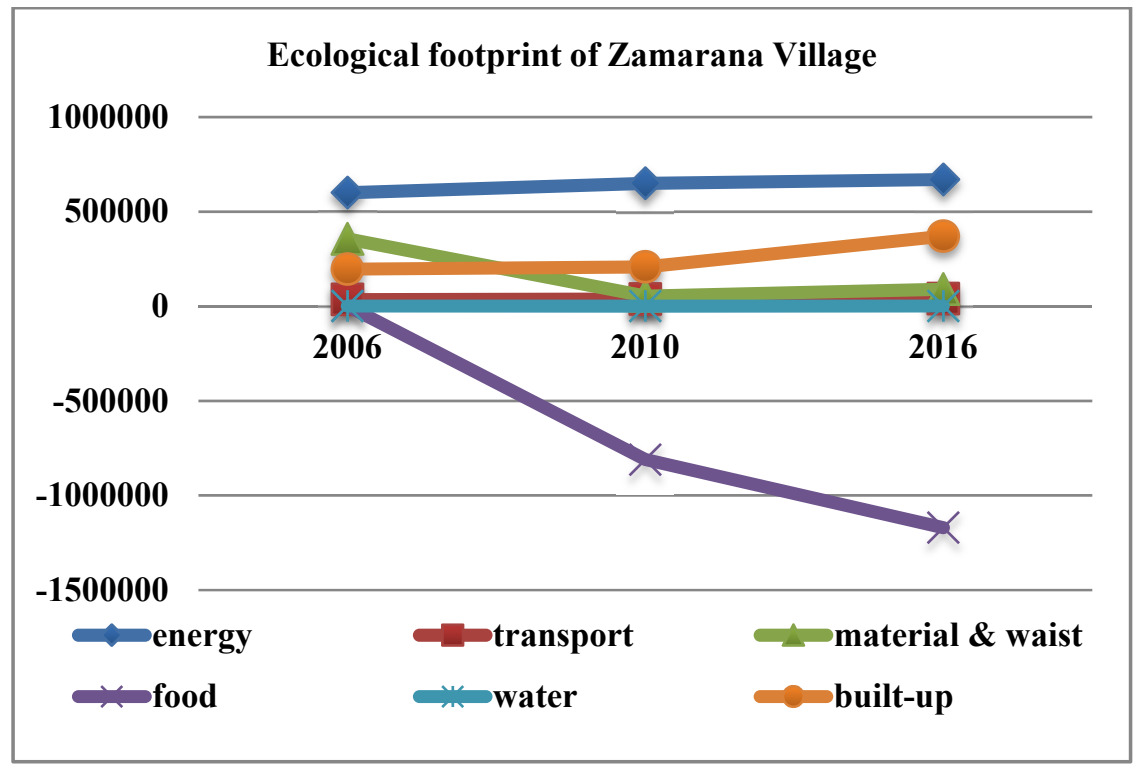

Figure 3: Ecological footprint of ZamaranaVillage. 
Comparing the ecological load with the ecological footprint we can detect that the village is ecologically sustainable and it adds up to the environment much more than what it consumes. Comparing the ecological footprint in 2016, which is $1 \mathrm{~m}^{2}$ and the ecological footprint in 2006 which was $580 \mathrm{~m}^{2}$ before carrying out the experiment, sustainable development in the village has been achieved to date through using the ecological footprint as a measure of sustainability, where the village had in 2006 an ecological footprint much more than its carrying capacity and after applying the experiment the current footprint has been less than its carrying capacity, which is an amazing achievement for sustainable development in rural areas in developing countries.

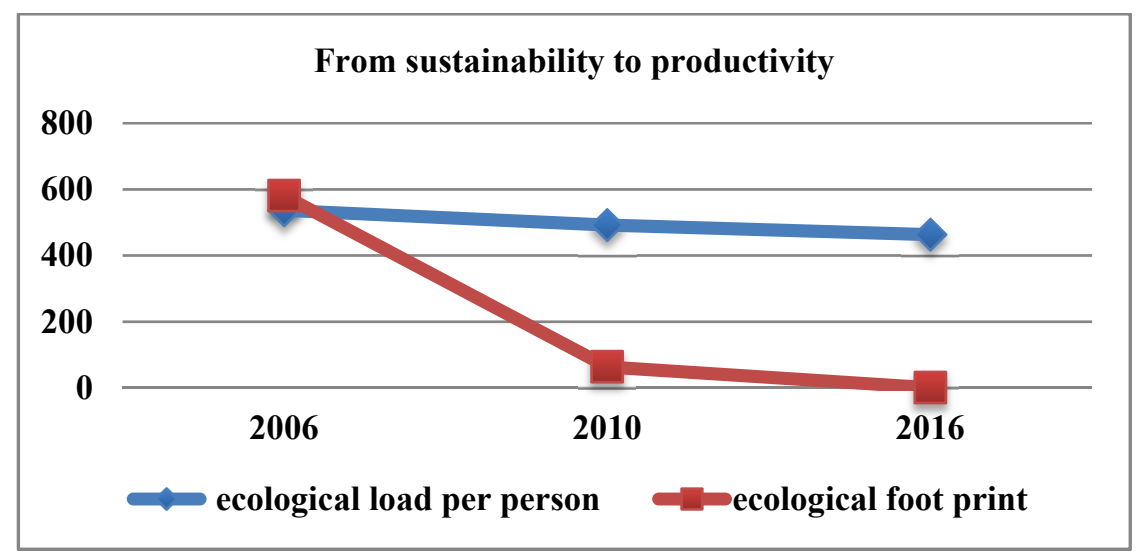

Figure 4: Comparison between ecological footprint and ecological load per person in Zamarana Village.

\section{Conclusion: achieving sustainable development and self- sufficient communities in the rural areas of Egypt}

After reviewing the Zamarna Village experiment in the sustainable development field, the main guidelines are easily formulated to be applied in any village and are as follows:

\subsection{Sustainable development projects in the rural areas of Egypt}

It is a national project to achieve a sustainable development in the rural areas of Egypt using modern scientific theories through civil societies and depending on the natural leadership and self efforts aiming to add to the national income.

\subsubsection{Aims of the projects}

- Changing of the passive harmful conduct.

- Developing teamwork spirit.

- Eliminating illiteracy.

- Facing unemployment and poverty. 


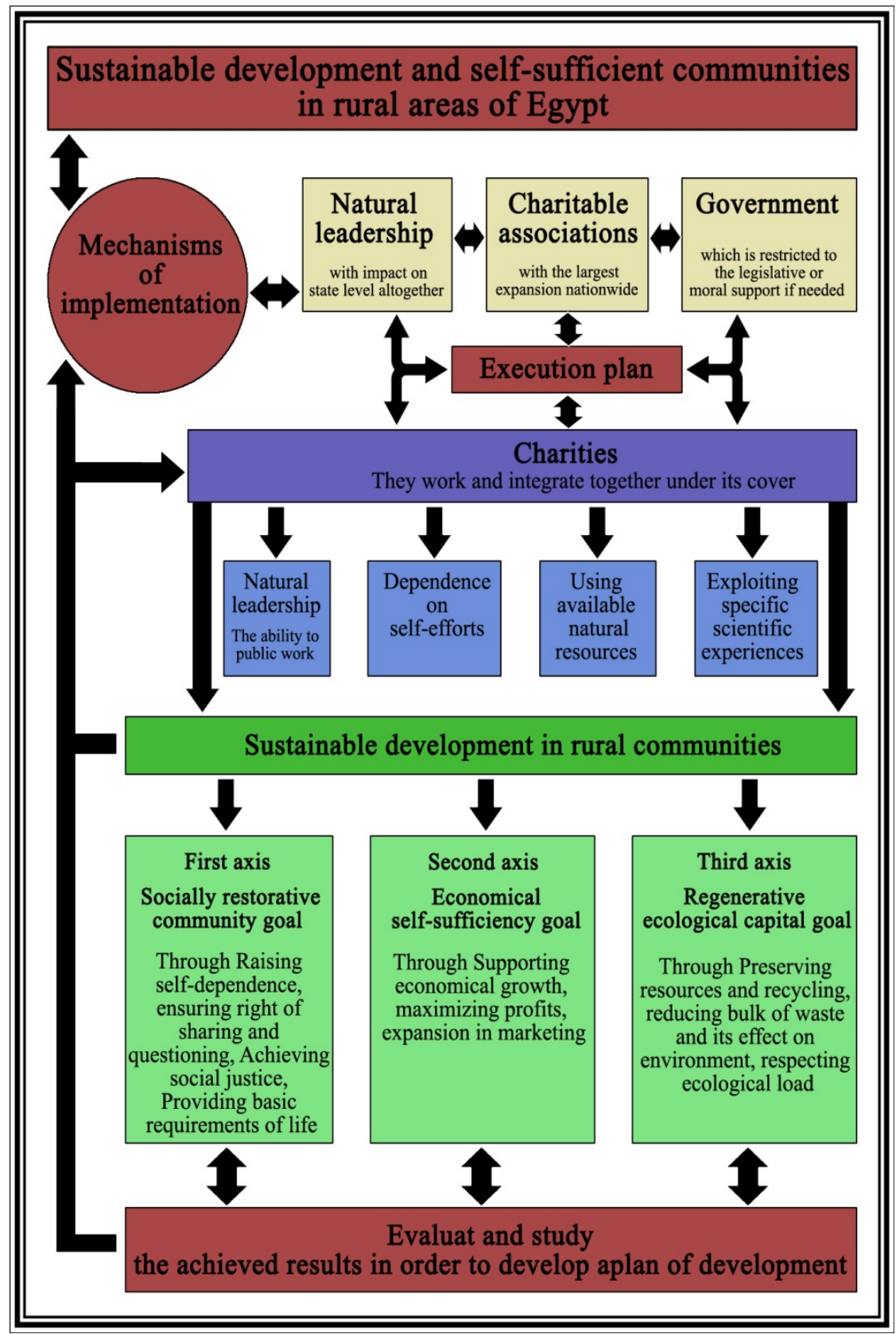

Figure 5: Sustainable development and self-sufficient communities in rural areas of Egypt. 
- Improving the level of individual income.

- Fighting illegal immigration.

- Respecting the ecological load to ensure the continuity of the development process.

- Effective addition to the national product.

\subsubsection{Mechanism of achievement}

The work is done through four basic mechanisms under the umbrella of charities. These four main mechanisms are: natural leadership that can do public work, dependence on self-efforts, using available natural mechanisms and utilizing specific scientific experiences in all the developmental fields.

\subsubsection{Role of the government}

Support of the project and replicating the experiment throughout Egypt.

Encouraging villages that achieve the aspired results as follows: paving roads, covering drainages in the inhabitant blocks and setting up sanitary networks.

\subsubsection{Development process}

To achieve sustainable development three axes are taken into consideration to assure the continuity of the development process and the continuous increase in the national product.

First axis: socially restorative community goal Raising self-dependence; through determining and selecting natural leadership that can do general work and depend on self efforts in providing all requirements whether through individual efforts or physical sharing, ensuring right of sharing and questioning; through increasing individual's sense of community responsibility and setting legislations and agreedon general rules regarding levying monetary or otherwise fines on who break them. Achieving social justice; through literacy and supporting poor cases, generally as a small project whose profits exceed minimum of living cost and expanding project of available and easy loan without interests, and providing basic requirements of life; through providing real job chances, supporting and setting mini projects and micro projects.

Second axis: economical self-sufficiency goal Supporting economical growth; through training, transferring of experiences, and fighting poverty and unemployment through easy loans. Maximizing profits; through the integration between the products of different projects and lowering the cost of production by making productive blocks for similar projects, and maximizing utility of available natural elements. Expansion in marketing; through setting marketing collective activities to expand in marketing different products for maximum profitability.

Third axis: regenerative ecological capital goal Reserving resources and recycling; through recycling agricultural waste and sorting out garbage at source and utilizing the soft garbage by converting it into manure and utilizing other types of garbage economically reducing the bulks of waste and its effect on the environment through safe disposal of the hazardous waste and paying attention to 
the individual and public hygiene and tree-planting, and rationalizing the consumption, through cultural forums, respecting the ecological load; through making the individual's lot of land enough to produce what a person consumes per year based on rationalizing the consumption and production-increase without increasing the individual's lot of land.

All these axes work in integration and correlation to ensure the achievement of the goals of development in the fastest and most effective ways.

\section{References}

[1] General census and statistical of Egypt in 2015, Central Agency for Public Mobilization Statistics (CAPMAS), pp. 11-15, 2015.

[2] Wackernagel, M. \& Rees, W. Our Ecological Footprint, New Society publishers, Canada, pp. 8-13, 1998 .

[3] Examining Success Factors for Sustainable Rural Development through the Integrated Co-operative Model, International Development Research Center (IDRC) web site, Canada, Funding projects, www.idrc.ca/en/project

[4] Chambers, N., Simmons, C. \& Wackernagel, M., Sharing Nature's Interest, Earthscan, London, pp. 80-98, 2007.

[5] Elboheira Governorate Annual Report, Elboheira Governorate information center, Egypt, pp. 20-25, 2015.

[6] Ismaiel, E.A., Personal communication, 15 January 2016, Board of director chairman, Zamarna Charity, Beheira Governorate, Egypt.

[7] Population Census and Statistical Year Book 2015, Central Agency for Public Mobilization Statistics (CAPMAS), pp. 4-9, 2015.

[8] Agriculture Census and Statistical Year Book 2015, Central Agency for Public Mobilization Statistics (CAPMAS), pp. 15-19, 2015.

[9] Environmental Census and Statistical Year Book 2015, Central Agency for Public Mobilization Statistics (CAPMAS), p. 20, 2015. 